\title{
Methodological issues in systems Human Factors and Ergonomics: Perspectives on the research-practice gap, reliability and validity, and prediction
}

\author{
Paul M. Salmon ${ }^{1}$ (1) | Gemma J. M. Read ${ }^{1}$ (1) | Guy H. Walker ${ }^{2}$ | \\ Nicholas J. Stevens ${ }^{1}$ (1) | Adam Hulme ${ }^{1}$ | Scott McLean ${ }^{1}$ | Neville A. Stanton ${ }^{3}$
}

${ }^{1}$ Centre for Human Factors and Sociotechnical Systems, University of the Sunshine Coast, Maroochydore, Queensland, Australia

${ }^{2}$ Institute for Infrastructure and Environment, Heriot-Watt University, Edinburgh,

Scotland, UK

${ }^{3}$ Transportation Research Group, University of Southampton, Southampton, UK

\section{Correspondence}

Paul M. Salmon, Centre for Human Factors and Sociotechnical Systems, University of the Sunshine Coast, Maroochydore, QId 4558, Australia.

Email: psalmon@usc.edu.au

\begin{abstract}
The changing nature of work and society, and a proliferation of complex global challenges, is increasing the need for systems Human Factors and Ergonomics (HFE). The discipline is well equipped to respond, but there remain a number of longstanding issues preventing systems HFE from realizing its full impact. There is a research-practice gap, a lack of reliability and validity evidence associated with systems HFE methods, and a shortage of methods that can predict behavior. In this article we revisit each issue, with each co-author providing their own perspective on the extent and causes of each issue, and their resolution. The perspectives reveal a consensus that the issues exist and are problematic but are challenging, multifactorial, and require various solutions. The findings are subsequently synthesized to form an agenda for the wider discipline.
\end{abstract}

\section{KEYWORDS}

Human Factors and Ergonomics, methods, prediction, reliability and validity, research-practice gap

\section{1 | INTRODUCTION}

Human Factors and Ergonomics (HFE) is "the scientific discipline concerned with the understanding of interactions among humans and other elements of a system, and the profession that applies theory, principles, data and methods to design in order to optimise human well-being and overall system performance" (IEA, 2019). The goal of the HFE practitioner is to understand and optimize individual, team, organizational, and system performance, both in work and societal systems. This is achieved through the application of a diverse set of HFE theories and methods which enable practitioners to:

1. describe and understand the behavior of individuals, teams, organizations, and systems; and

2. direct the design and evaluation of products, tools, devices, work and tasks, environments, training programs, procedures, policy and regulation, and overall sociotechnical systems.
HFE is therefore about understanding and optimizing performance to enhance efficiency, productivity, safety, and ultimately human health and well-being. HFE work has had far-reaching impacts on the design of work and societal systems since its emergence shortly after the second World War (Waterson \& Sell, 2006). The need and demand for HFE is increasing. Work and societal systems are becoming increasingly complex and reliant on new and sophisticated forms of technology. Dramatic changes are being brought about by artificial intelligence, automation, big data, and the internet of things (Holman, Walker, Lansdown, Salmon, et al., 2020). Moreover, HFE can, and should, be playing a leading role in the response to complex global challenges such as climate change and environmental degradation, extreme weather, overpopulation, food and water security, disease, misuse of the internet and social media, terrorism, cybercrime, nuclear warfare, inequality, antimicrobial resistance, and instability in the world's economy (Salmon et al., 2019; Thatcher et al., 2018). HFE has a critical role to play in our future. 
The issues above are highly complex. Accordingly, since the turn of the century there has been a growing body of work in which so called "systems HFE" methods are being applied to understand and respond to complex problems (Karsh et al., 2014; Salmon, Walker, et al, 2017; Walker et al., 2017; J. Wilson, 2006). These methods provide the capacity to model the structure and behavior of complex systems, the outputs of which support the identification of leverage points and development of new interventions which can have significant effects on behavior (Salmon et al., 2019). While the demand for systems HFE has increased dramatically in recent years, there are a number of fundamental challenges which impact on the contribution that systems HFE can make (see discussions by Hancock, 2019; Karwowski, 2005; Salmon, 2016; Salmon, Walker, et al., 2017; Shorrock \& Williams, 2016; Stanton, 2016). These are particularly centered on the systems HFE methods that researchers and practitioners use to understand and respond to complex problems. While it is acknowledged that there are various issues, in this article we focus on the following:

1. The research-practice gap (Shorrock \& Williams, 2016). This refers to an alleged gap between the systems HFE theories and methods being applied by researchers and practitioners. Specifically, that state-of-the art systems HFE methods used in research are not being applied in practice (Salmon, 2016; Shorrock \& Williams, 2016);

2. The reliability and validity of HFE methods (Stanton, 2016). The reliability and validity of HFE methods has long been a cause for concern (Annett, 2002; Stanton \& Young, 1999a). For many systems HFE methods it is not clear whether they actually produce valid and reliable outputs. In 1999, HFE was challenged to prove that their methods actually do all what is claimed of them (Stanton \& Young, 1999a, 1999b). In the case of systems HFE, over two decades later, there has been little response to that challenge (Stanton, 2016).

3. The capacity for HFE methods to predict behavior (Moray, 2008; Salmon, Walker, et al., 2017). A major strength of systems HFE methods is they can usefully describe and analyze the behavior of individuals, teams, organizations, and sociotechnical systems. A major limitation is that most methods do not provide the capacity to simulate or predict behavior (Salmon et al., 2020). This has been labeled the greatest challenge facing HFE (Moray, 2008; Salmon, Walker, et al., 2017).

In this article we revisit each issue based on discussions held at a residential research center writing retreat on K'gari (Fraser Island, located off the eastern coast of Australia). The aim was to enable researchers currently applying systems HFE in a range of domains to construct their own narratives about why these challenges arise, and how they can be resolved. Issues relating to physical and cognitive HFE were considered beyond the scope of the article, with the authors being instructed to focus on systems HFE only. Each co-author provided their own perspective on the three issues described above, based on their diverse experiences in systems HFE research and practice. The co-authors comprise senior HFE researchers, early career HFE researchers (ECR), and researchers from other domains who are currently working in the area of HFE (see Table 1).

\section{I THE RESEARCH-PRACTICE GAP}

The research-practice gap in HFE is characterized by discrepancies in the theories and methodologies that HFE researchers and practitioners apply in response to the same issues (Salmon, 2016; Shorrock \& Williams, 2016). A key concern is the extent to which the methods used by HFE practitioners reflect the theoretical and methodological advances being made in research. In short, state-ofthe-art systems HFE theories and methods may not be being applied in practice. This can potentially have many consequences, including the use of methods that are not fit for purpose and the generation of outputs that may be misleading or inaccurate.

The research-practice gap appears to be especially prominent in systems HFE. As many systems HFE methods are relatively new (e.g., Dallat et al., 2018; Hollnagel, 2012; Leveson, 2004, 2011; Stanton et al., 2018; Vicente, 1999) and are often difficult and time consuming to apply, they have yet to be widely adopted in practice. Salmon (2016) describes the implications of this in relation to accident analysis and investigation, a core focus of systems HFE. In this context researchers are currently applying advanced systems HFE methodologies such as Accimap (Svedung \& Rasmussen, 2002), the Systems Theoretic Accident Model and Processes (Leveson, 2004), and the Functional Resonance Analysis Method (FRAM; Hollnagel, 2012), and it is not unusual for studies using older methods to now be rejected by journals. Many practitioners, on the other hand, continue to apply older methods, such as the Human Factors Analysis and Classification Scheme (HFACS; Wiegmann \& Shappell, 2003), root cause analysis (P. F. Wilson et al., 1993), the BowTie method (de Ruijter \& Guldenmund, 2016), and Reason's ubiquitous Swiss cheese model (Reason, 1990). While these methods have known limitations and are not aligned with current state-of-the-art models, they remain popular with practitioners (Hulme et al., 2019).

The impact of the research-practice gap is problematic. Systems HFE methods need to be matched to the problems they are tasked with solving. A rise in systemic problems which is not matched with a corresponding rise in applying systems HFE methods threatens the core validity of HFE as a discipline (Holman, Walker, Lansdown, Salmon, et al., 2020). The analyses produced may be out of date, invalid, misleading, and even dangerous (Salmon, 2016). The issue is not limited to accident analysis and investigation. Similar patterns are being reported in research and practice in relation to other key systems HFE constructs such as situation awareness (Dekker, 2015), teamwork (Stanton et al., 2013), and risk assessment (Dallat et al., 2018).

Each co-author was asked to respond to three questions about the research-practice gap, its impact, and its resolution. 
TABLE 1 Co-authors' experience, publications, and domains worked in (authors are de-identified for blinded review process)

\begin{tabular}{|c|c|c|c|c|c|}
\hline Author & Current position & $\begin{array}{l}\text { Year PhD award } \\
\text { and topic }\end{array}$ & $\begin{array}{l}\text { Years' experience } \\
\text { applying HFE } \\
\text { methods }\end{array}$ & $\begin{array}{l}\text { Number of peer-reviewed } \\
\text { HFE journal articles, } \\
\text { citations, and } \mathrm{H} \text { Index } \\
\text { (Scopus, June 2020) }\end{array}$ & $\begin{array}{l}\text { Domains worked in (based on } \\
\text { publications) }\end{array}$ \\
\hline Hulme & $\begin{array}{l}\text { Post-Doctoral } \\
\text { Research } \\
\text { Fellow in } \\
\text { Human } \\
\text { Factors }\end{array}$ & $\begin{array}{l}\text { 2017, Epidemiology } \\
\text { and Human } \\
\text { Factors and } \\
\text { Ergonomics }\end{array}$ & 4 & $\begin{array}{l}\text { Journal articles }=13 \\
\mathrm{H} \text { Index }=9 \\
\text { Citations } 218\end{array}$ & $\begin{array}{l}\text { Sports injury } \\
\text { Safety in HFE (current focus, multiple } \\
\text { domains) }\end{array}$ \\
\hline McLean & $\begin{array}{l}\text { Post-Doctoral } \\
\text { Research } \\
\text { Fellow in } \\
\text { Human } \\
\text { Factors }\end{array}$ & $\begin{array}{l}\text { 2018, Human Factors } \\
\text { and Ergonomics/ } \\
\text { Sports Science }\end{array}$ & 4 & $\begin{array}{l}\text { Journal articles }=18 \\
\text { H-Index }=4 \\
44 \text { citations }\end{array}$ & $\begin{array}{l}\text { Sport (performance, injury), Outdoor } \\
\text { recreation, Road }\end{array}$ \\
\hline Salmon & $\begin{array}{l}\text { Professor Human } \\
\text { Factors }\end{array}$ & $\begin{array}{l}\text { 2008, Human Factors } \\
\text { and Ergonomics }\end{array}$ & 20 & $\begin{array}{l}\text { Journal articles }=214 \\
\mathrm{H} \text { Index }=43 \\
6011 \text { citations }\end{array}$ & $\begin{array}{l}\text { Defence (Land, Air, Sea), Road, Rail, } \\
\text { Aviation, Maritime, Sport, Outdoor } \\
\text { recreation, Retail, Freight, } \\
\text { Healthcare, Cybersecurity, Mining, } \\
\text { Disaster and emergency response, } \\
\text { Urban design, law enforcement }\end{array}$ \\
\hline Stanton & $\begin{array}{l}\text { Professor Human } \\
\text { Factors }\end{array}$ & $\begin{array}{c}1993 \text { Human Factors } \\
\text { and Ergonomics }\end{array}$ & 36 & $\begin{array}{l}\text { Journal articles }=506 \\
\mathrm{H} \text {-index }=56 \\
11,237 \text { citations }\end{array}$ & $\begin{array}{l}\text { Automation, Civil Aviation, Defence } \\
\text { (Land, Air, Sea), Disaster, Emergency } \\
\text { response, Energy Distribution, } \\
\text { Maritime, Oil and Gas, Product } \\
\text { Design, Rail, Road, Urban design }\end{array}$ \\
\hline
\end{tabular}

Abbreviation: HFE, Human Factors and Ergonomics.

\section{1 | Do you see a significant research-practice gap in HFE?}

Salmon: "Yes. I have seen lots of first-hand evidence of a research practice gap in many domains. Much of what I have seen relates to the models and methods used for accident analysis and investigation; however, the gap is also apparent in other areas such as systems analysis, HFE in design, and situation awareness assessment."

Read: "Yes, I believe that a gap exists across a range of areas. I would add that the gap can be seen in the theories and methods applied, but also in relation to the implementation of research findings to support system design. In my experience as a practitioner, our team would look to apply best practice where possible, but a number of constraints affect the ability to achieve this fully."

Hulme: "I can only really speak from the perspective of sports injury prevention research. However, I have my reservations regarding the practical impact that HFE research has-and is having-in the field of sports science and injury prevention research. Systemic HFE models are undoubtedly useful at identifying the interrelationships among multiple agents and factors in a given 'sports system', but how to make a tangible, measurable difference to the lives of athletes is an area of HFE research that should be subjected to further scholarly conversation." 
Walker: "According to the Oxford dictionary, a practitioner is a person actively engaged in an art, discipline, or profession. I therefore reject the premise of the question...to an extent at least. In an applied discipline surely we are all practitioners? I can't personally think of any pure 'theoretical ergonomists' in the same way we might think of a pure mathematician. We may all be practitioners but what we practice, where, and for whom often varies significantly. There is a gap. A big and fundamental gap, albeit one not related to the false dichotomy of 'research' and 'practice'. It's worse than that."

McLean: "Yes. Practitioners applying HFE methods in a sports performance context is rare. The professional and international sporting organisations I have worked with over the past few years do not use HFE methods in practice. However, in my personal experiences via practitioner feedback, when applied, HFE research applications to sporting performance have been well received and practitioners have enjoyed and benefited from what HFE methods can bring to sport science."

Stanton: "No! As both an academic researcher and consultant, I am able to implement the very latest research into practice in all my consulting activities. Whilst I accept that many practitioners may lag behind the cutting edge of research, there is no reason why they should. In some recent consulting to the Healthcare Safety Investigation Branch, I was able to teach them the Actor Map and AcciMap methods relatively quickly (within one day) whilst we investigated an incident together. This is indicative of the work that I have conducted with vehicle manufacturers, energy generation and distribution companies, and safety organisations. In my opinion, there is a professional obligation on behalf of everyone in the discipline to remain current with contemporary trends in research and develop his or her knowledge and skills."

Stevens: "In HFE I am becoming more aware of it. I have certainly recognised it in my own urban development discipline. There we are in fact largely practice led-which is troubling considering the current social and environmental crises. Practice leading practice is self-fulfilling prophecy of commercially driven outcomes where community and society comes last. As a recent convert to HFE and its methods, I recognise that these approaches, particularly systems approaches, can offer much for the practical exploration and dismantling of the 'business-as-usual' world we live in. I am a little surprised there is such a gap in HFE."

\section{2 | Why do you think the research-practice gap exists?}

Salmon: "It is a complex problem. On one side you have a set of constraints that practitioners face when attempting to apply systems HFE in practice (see Shorrock \& Williams, 2016), and on the other you have a set of constraints which are pushing researchers to advance the science and create new models and methods (see Williams \& Salmon, 2016). I think because of these issues practitioners struggle to keep pace with new theories and methods, and so stick with what they know and have used previously."
Read: "It is a multifaceted issue, which as with all HFE challenges involves the interaction between factors at the individual, organisational and wider systems levels. At an individual level, researchers may not have the knowledge and skills to communicate their research in a way that assists practitioners to use it, and practitioners may not have the knowledge or skills to critique and appropriately apply theories, methods or research findings. At an organisational level, practitioners may not be provided with the resources to support them to apply research. For example, it is hardly surprising that negotiating the HFE literature is a challenge for practitioners (indeed it can be a challenge for researchers as well!). A Google Scholar search for "teamwork" provides 41,200 results. These results provide various theoretical and methodological approaches, which potentially conflict. Without access to publications sitting behind a paywall, a lack of time to conduct a thorough literature review nor mentoring from discipline leaders, how can the practitioner synthesise this literature in a way that allows them to determine the best theoretical or methodological approach to follow to solve the challenges they are facing in their work?"

Hulme: "First, I think that injury prevention researchers in the sports science and epidemiological fields have simply not been adequately exposed to HFE methods and analyses. For this reason, there is a need to continue to promote HFE methods and analyses among the sports science and injury prevention communities. Second, and somewhat more contentious, I think that sports scientists and epidemiologists, including biostatisticians, might perceive HFE methods and analyses as less 'rigourous' and therefore unfit to be used as a basis to guide injury prevention interventions. This comes back to the 'soft' versus 'hard' science dichotomy, including attitudes towards qualitative and quantitative research approaches. Such attitudes are attributable to differing philosophies and personal perspectives towards how research could (and should) be designed and conducted more generally. For HFE approaches to have practical impact down the line, it may well be necessary to firstly addresses underlying personal biases and predilections towards how reality is understood and the science behind it applied."

Walker: "If the so-called 'value proposition' of HFE is as it should be, we would be overwhelmed with demand for state-of-the-art systems methods, with those working in consulting and industry clamouring for them and partnering with academia as fast as they can (and vice versa). It happens in other fields, like engineering and the physical sciences, where the latest scientific developments are converted (commercialised?) into useful things that are perceived to be of value. But generally speaking, that is not happening in our world, at least not at any scale, despite some brilliant examples of what can happen when it does. In the main, the kind of work associated with 'research' is not valued in the same way by the consumers of 'practice', so in my view it's a more fundamental, disciplinewide 'value gap'. Whether, and for whom future values will align is at present unknown, but I often ponder whether a client would ever ask a rocket scientist to distil their entire discipline "into three short, easy to understand bullet points". I somehow doubt it, and therein 
lies the problem. Faulty perceptions of value, at least right up until the point at which yet another complex emergent phenomenon bounces out of the ether to scare us witless. Unfortunately, at that point it is normally too late for HFE to fully demonstrate its value proposition and the cycle repeats."

McLean: "I think the lack of exposure to HFE and systems thinking methods in sport science education is the main issue. No sport science degree that I am aware of has a HFE or systems thinking component teaching the benefits of HFE methods. Personally, I completed a sport science degree and a research Masters degree in exercise physiology before I was even aware of HFE methods and their potential for understanding sports performance."

Stanton: "I think that the research-practice gap only exists in the minds of people who are not putting research into practice. I am working with many commercial organisations in vehicle automation, flight deck design, control room design, and safety. The benefit of working directly with an original equipment manufacturer is that research is put into practice as a matter of course. In one example from the early 1990s, I was working with Jaguar Cars (now Jaguar LandRover) on adaptive cruise control. We helped Jaguar design the driver interface for the Adaptive Cruise Control (ACC) system that led to a production vehicle in 1999 (making Jaguar the first to market with $\mathrm{ACC}$ ), winning some design awards along the way. Whilst I accept that it can take some years for the research to lead to practice, research-based evidence can be very persuasive for including HFE considerations in design."

Stevens: "In my opinion it is time and money (motivation). This is the same regardless of discipline. Industry have approaches they understand, they know how much to budget for them, they get the right political data they were after-so why complicate it? New approaches are seen to cost time and money; they believe they are already getting the right answers. Further, the profile of academics by industry could do with a makeover-there is still a perception that much of the work is pie in the sky-unfortunately there is a legacy of academic achievement that has left industry cold."

\subsection{How can the research-practice gap be closed?}

Salmon: "I think work is required on both sides. Researchers can be more cognisant of the constraints that practitioners work under, and practitioners can place more emphasis on engaging with researchers and being aware of the latest research developments. Partnerships between academia and Industry are vital, as they enable researchers and practitioners to work together and co-develop state-of-the-art methods for use in practice. Our Understanding and Preventing Led Outdoor Accidents Data System (UPLOADS; Goode et al., 2018; Salmon, Goode, et al., 2017) program is a good example of this. Based on an industry partnership we developed an incident reporting and learning system that is underpinned by Rasmussen's risk management framework and involves the use of AcciMap to analyse led outdoor activity incidents. The development process was an extensive collaboration between researchers and practitioners, involving various studies and activities that were designed to identify key end-user needs and to upskill practitioners in the methods (Goode et al., 2018). As a result, UPLOADS is now used by many organisations, whilst at the same time being recognised as state-ofthe-art in terms of accident theory and analysis methods. Without the partnership, this would not be the case."

Read: "We often hear that "safety is a shared responsibility" and I think we could expand this concept of a shared responsibility to the translation of HFE research into practice. We need our wider organisational systems to support us to develop meaningful collaborations where sufficient time and resources are available to conduct good quality, leading-edge research which addresses the priority issues for industry and government. While academia is moving towards measuring and rewarding research translation and research impact, publications remain a key measure. Further, the rewards for practitioners to engage more with research and researchers are highly dependent on the constraints imposed by their organisations, and the culture of senior management, etc. On a practical level, more industry linked programs, where PhD students and/or early career researchers are embedded within organisations might help to close the gap, by creating a better understanding each other's worldviews, constraints and attitudes."

Hulme: "First, I think there is a lack of an intermediary process of some form connecting academia with the people on the ground. For example, HFE academics working within a higher education institution conduct research, usually as the so-called "experts", and subsequently aim to publish their findings in a reputable peer reviewed journal. Much of this work can have a large theoretical component, and is equally written and articulated in such a way that the intended beneficiaries can be left asking: what are the real implications for me? How can I use these insights and results and translate them to inform practice? Of course, practitioners and industry need to be exposed to HFE research before such questions are even raised, and potential solutions to encourage greater awareness should be explored. Second, I would like to emphasise the importance of approaching the end-users during the planning phases of research, ascertain what problems require solving and why, and then proceed with HFE research activities. This would facilitate ongoing collaborations, allowing the HFE researcher to understand the specific needs and implementation context that can enable or hinder the implementation of a given solution or intervention. The previous UPLOADS (Goode et al., 2018; Salmon, Goode, et al., 2017) example is a case in point of how established industry partnerships can be mutually beneficial to all parties. What is found to be efficacious under controlled circumstances is not automatically effective in a real-world situation, and so personal insights can help to close this gap."

Walker: "There are a number of options, some more depressing than others. Option 1 is to work in partnership, but it is an increasingly naive hope. For a while now the message, tacit or otherwise, has been that academic outputs are of little practical value and that 'practice'-where the 'real' HFE work is assumed to occur-need types of output that research does not, or cannot deliver. My feeling 
is that despite efforts made on the research side there is scant movement towards applying latest developments in practice. Industrial advisory panels on projects far out-weigh scientific or academic advisory panels. The world of research has, by and large, listened and responded to exhortations for practitioner impact but it has not been reciprocated. In practice, methods dating from the 60 's and the third industrial revolution (3IR) are in routine use whether they are appropriate or not (Holman, Walker, Lansdown, Salmon, et al., 2020; Walker et al., 2010). Let us ask the question we dare not ask: is the discipline slowly ossifying despite a period of unprecedented global change, when human-centred solutions are needed more now than ever?

Let's cheer ourselves up (but only slightly) with Option 2, which is to face into the 'value gap'. The dawning fourth industrial revolution (4IR) will rapidly overwhelm the discipline as we know it today, meaning that HFE value will have to be added elsewhere. Many research grand challenges in engineering, for example, are ergonomic and human-centred in all but name. These are where the 'high quality' systems problems (e.g. Dul et al., 2012) increasingly reside, and where a deeply-systemic HFE perspective is welcomed. Goodbye 3IR HFE, it's been nice knowing you. Welcome to the 4IR."

McLean: "I believe exposure to HFE and systems thinking methods are key to closing the gap. If HFE and systems thinking methods were introduced to sport science students at an early stage in their education, these methods might well become valuable practitioner tools, which at present is not the case. In addition, as HFE methods eventually become more popular in elite sport there are a few issues to be avoided which could create gaps and reduce practitioner engagement. Firstly, research populations need to match the population where practical applications are intended e.g. research with an under 12 football team cannot be transferred to a premier league team. Secondly, cut the fluff. HFE researchers need to be aware that elite coaches have very limited time (and understanding of HFE methods) and succinct but accurate explanations of outputs are key to engagement, which can be challenging given the complexity of HFE methods. Lastly, design research as best as possible to avoid major distractions to elite teams, elite sport is very structured and coaches don't like to deviate from plans and training schedules."

Stanton: "It seems fairly obvious to me the HFE is such a complex subject that one needs a doctorate before beginning to put it into practice. It is all too easy to do HFE badly. I am aware of people in the profession calling themselves HFE specialists without any grounding in the subject matter. I am also well aware that a Bachelors or Masters degree is scant preparation for tackling the complexity of sociotechnical systems. A research doctorate provides excellent training for putting research into practice, providing an apprenticeship in problem analysis and problem-solving, interpersonal and leadership skills, project management and organization, research and information management, self-management, and written and oral communication skills. We need to up-skill the entire profession if we hope to close the perception of the research-practice gap (one which is already closed in my own professional practice). Raising the professional status of our discipline has many benefits, as it should bring researcher and practitioners closer together."

Stevens: "It will require academia to lead the process, build trust and demonstrate efficacy in the methods and approaches that industry could be using in their decision-making. It is however a process that can begin when undergraduate teaching is being delivered in a range of disciplines. Students attend universities to gain insight into theory and practice-it is what separates university from technical colleges. Students (practitioners in training) need to understand the value and importance of research and scientific enquiry for decision-making. Academia, both research and teaching, need to be mutually supportive and articulate to the practitioners of the future that practice that does not draw on science that is fundamentally flawed. To support those practitioners currently making the decisions; standards of quality science and rigour must be mandatory components of government project tendering-a major source of consultant work."

\section{4 | Summary of perspectives on research-practice gap}

A summary of each perspective on the research-practice gap is presented in Table 2.

\section{I THE RELIABILITY AND VALIDITY OF HFE METHODS}

Reliability and validity testing is critical to ensure that HFE methods actually work as intended (Annett, 2002; Stanton, 2016; Stanton \& Young, 1999a). While there is a long history of work attempting to verify the reliability and validity of HFE methods, there is scant evidence available for systems HFE (Thoroman et al., 2020). Consequently, it is not actually clear that systems HFE methods measure or describe what they intend to or that the analyses produced are repeatable across different analysts and applications. Indeed, initial attempts at assessing the reliability and validity of systems HFE methods have returned poor or moderate results (Cornelissen et al., 2014; Goncalves Filho et al., 2019; Good et al., 2017, 2018). For the present commentary, each co-author was asked to respond to two questions regarding the requirement for HFE methods to have evidence demonstrating their reliability and validity, and why the reliability and validity of HFE methods is seldom tested.

\section{1 | Do all HFE methods require evidence of reliability and validity?}

Read: "I don't agree that all methods must have evidence of standard reliability and validity to be useful. Annett (2002) argued that the validity of evaluative methods (i.e. tests that aim to measure a parameter, such as workload or fatigue) should be distinguished from the validity standards required of analytical methods (i.e. those that 
TABLE 2 A summary of perspectives on the research-practice gap in HFE (authors are de-identified for blinded review process)

\begin{tabular}{|c|c|c|c|}
\hline Author & $\begin{array}{l}\text { Do you see a significant } \\
\text { research-practice gap in HFE? }\end{array}$ & $\begin{array}{l}\text { Why do you think the research-practice gap } \\
\text { exists? }\end{array}$ & How can the research-practice gap be closed? \\
\hline \multirow[t]{2}{*}{ Salmon } & \multirow[t]{2}{*}{ Yes } & $\begin{array}{l}\text { 1. Practitioner constraints preventing the uptake } \\
\text { of HFE theory and methods. }\end{array}$ & 1. Partnerships between academia and industry. \\
\hline & & $\begin{array}{l}\text { 2. Researcher constraints impacting the design } \\
\text { and communication of theory and methods. }\end{array}$ & $\begin{array}{l}\text { 2. Researchers being more cognizant of } \\
\text { practitioner constraints. }\end{array}$ \\
\hline \multirow[t]{3}{*}{ Read } & \multirow[t]{3}{*}{ Yes } & $\begin{array}{l}\text { 1. Researcher lack of knowledge and skills } \\
\text { around research communication. }\end{array}$ & $\begin{array}{l}\text { 1. Organizational support for practitioners to } \\
\text { engage with researchers and academia. }\end{array}$ \\
\hline & & $\begin{array}{l}\text { 2. Practitioner lack of knowledge and skills on } \\
\text { how to apply state-of-the-art theory and } \\
\text { methods. }\end{array}$ & $\begin{array}{l}\text { 2. Organizational support for practitioners to } \\
\text { implement new theory and methods. }\end{array}$ \\
\hline & & $\begin{array}{l}\text { 3. Lack of organizational support for } \\
\text { practitioners in implementing new methods. }\end{array}$ & $\begin{array}{l}\text { 3. Support for the development of meaningful } \\
\text { partnerships between academia and industry. }\end{array}$ \\
\hline Walker & No & $\begin{array}{l}\text { 1. Limited value placed on HFE research by } \\
\text { practitioners. }\end{array}$ & $\begin{array}{l}\text { 1. Partnerships between academia and industry. } \\
\text { 2. Align more closely with other disciplines/ } \\
\text { subsume ourselves into them. }\end{array}$ \\
\hline \multirow[t]{3}{*}{ McLean } & \multirow[t]{3}{*}{ Yes } & \multirow[t]{3}{*}{$\begin{array}{l}\text { 1. Lack of practitioner exposure to state-of-the- } \\
\text { art HFE methods. }\end{array}$} & $\begin{array}{l}\text { 1. Closer alignment between research study } \\
\text { samples and end-user populations. }\end{array}$ \\
\hline & & & $\begin{array}{l}\text { 2. More succinct and understandable } \\
\text { communication of research outputs and } \\
\text { method. }\end{array}$ \\
\hline & & & $\begin{array}{l}\text { 3. Improved research study design to better } \\
\text { align with practitioner needs. }\end{array}$ \\
\hline
\end{tabular}

Abbreviation: HFE, Human Factors and Ergonomics.

aim to understand complex systems). For evaluative methods, reliability is achieved when results from independent samples agree. For analytic methods, reliability is achieved where data collection conforms to the model that underpins the method. So, I think the purpose of the method being considered should drive the requirements for reliability and validity. It may be inappropriate to hold HFE methods for understanding and modelling complex systems to the same standard as those that set out to measure a construct or parameter."

Salmon: "It is definitely important to ensure that HFE methods actually do what they aim to do (validity); however, my feeling is reliability is not so clear cut. For example, we have found recently that inter-rater reliability can be misleading, particular when using systems HFE methods. For example, when either conducting systems analyses (e.g. AcciMap; Svedung \& Rasmussen, 2002) or attempting to identify risks across an entire sociotechnical system (e.g. NetHARMS; Dallat et al., 2018), the analyses are always richer and more comprehensive if we use multiple analysts from different parts of the system (e.g. front line staff, supervisor, manager, COE, regulator, government). Here they produce entirely different analyses based on their own view and experience of their own part of the system in which they work, and when these analyses are combined it becomes extremely comprehensive. This of course represents low inter-rater reliability; however, the outputs are more valid as a result."

Stevens: "All methods of research enquiry, HFE or otherwise, are only inherently useful if they are valid and assist in examining and elucidating the challenges to which they were tasked. Further, if the validity of an approach is clearly demonstrated there are greater opportunities for uptake and deployment both in research and practice. However, maintaining the reliability of methods is perhaps more difficult in some domains than others. The use of objective and technically generated data sets will always allow for higher degrees of reliability. Yet, the more subjective and arguably more complex pursuits, of sociotechnical and systems thinking approaches reliability is perhaps less 
confident. In my opinion this uncertainty is not holistically detrimental or at odds with the generation and pursuit of new knowledge."

Stanton: "It concerns me that this question even has to be asked, as says quite a lot about the status of the HFE discipline. If, as a profession, we said we had no idea if our methods were reliable or valid then why should anyone take us seriously? It can be difficult enough to get HFE into projects, without this threat to our professional credibility. It has to be the goal of the profession to establish the reliability and validity of our methods, across a range of domains and applications. This can only improve our standing, and the likelihood that we will be taken seriously, amongst other engineering professions."

\subsection{Why is the reliability and validity of HFE methods not often tested? How can this be resolved?}

Walker: "We need to remember that the HFE paradigms we are attempting to measure are just human constructs, not natural phenomena (Rifkin, 2014). You could argue that the traditional conception of reliability and validity is deterministic in nature, suited to deterministic problems and methods: if the system being analysed is well understood and formalised, then knowledge of that system can be generated reliably and repeatably. But is HFE really like that? Actually, the fundamental HFE 'paradigm' is rooted in subtle realism (Walker, 2016). A physical reality, and its universal properties, are assumed to exist objectively 'behind' human perception, but HFE's ability to know this reality is limited by the methods at our disposal. This is why we have so many! We also operate within an epistemology rooted in transactionalism. We generate conceptual models of reality (i.e. situation awareness, mental workload, etc.) which we reinforce or deselect through an interactive sense-making process within a social context. At the end of the day, then, as HFE participants we are pragmatic, transactional, subtle realists. We are not Newtonian physicists. This makes issues of reliability and validity more complex and nuanced than they appear. It is no wonder they are so rarely subject to explicit testing."

Read: "Where the type of method calls for tests of reliability and validity, I think that it is important for this to be undertaken as part of the development process. HFE is a scientific discipline and risks being undermined or ignored when we edge too close to pragmatism and away from scientific robustness. I sometimes wonder about the number of new methods, and adaptations to existing methods, being developed within academia. Perhaps the sheer scale of methods impacts on the ability to fully test methods across different contexts and domains. Perhaps if we could gain some consensus on a core set of methods and approaches, based on the needs of practitioners, and embark on collaborative, longitudinal program of research to comprehensively test these methods, this could provide a way forward."

Salmon: "Formal reliability and validity studies are difficult to run and require a lot of resources. They are complicated to design, it is difficult to recruit a sufficient number of participants (they often have to perform a time consuming analysis twice), you often need an expert panel comprising multiple subject matter experts, or a gold standard set of analyses, and you have to make sure all participants receive the same training in a particular method. On top of this, the analysis of data is resource intensive and time consuming (the data from a study we recently conducted took well over 6 months to analyse). Finally, there is limited guidance on appropriate methods and statistical tests to use."

McLean: "In my experiences I don't think HFE researchers are as concerned with reliability and validity as other disciplines such as sport science, or psychology. A possible recommendation could be for HFE researchers to consult with statisticians in the design of research."

Stevens: "It is important to note that the testing of the validity and reliability of methods is not a challenge solely attributable to HFE. In the urban development discipline and within the social sciences studies of urban life there are also deficiencies. In part, I recognise that the challenge lies in the quantity and quality of the doctorate studies and the quality of the supervision being imparted which has underlying implications for the methodological rigour. There is a need for current and supervising academics, of all disciplines, to ensure they are also research productive academics with knowledge of state-of-the-art approaches."

Hulme: "After reading in more detail about reliability and validity in the HFE literature during my post-doctoral studies, it struck me just how nuanced and particular these concepts can be. For example, I soon realised there was intra- and inter-rater reliability, test-retest reliability, parallel forms reliability, internal consistency reliability, criterion validity, content validity, and construct validity. Each of these terms, of which can be further broken down into subcategories, highlight that reliability and validity training, testing, and practice requires careful consideration on behalf of the researcher. In short, I am not entirely sure why reliability and validity have not been prioritised in the HFE safety science literature, but can only speculate that doing so is viewed as too great a challenge given the knowledge and expertise surrounding it?"

Stanton: "My approach has always been to conduct formal studies of reliability and validity, and to report the findings in the peer-reviewed literature (Stanton, 2016). Ideally, it should be possible to demonstrate that a HFE method will produce the same results if it is used by different people or on different occasions by the same people. A method is generally considered to have minimally acceptable reliability if the method's expert creator could achieve repeatable results on different occasions. At the other extreme would be a method that delivered the same results when used by anyone with even a little training. Between these extremes would be most of the methods used in HFE. Whether any one of these would be considered to have an acceptable degree of reliability would depend on a variety of factors, including: analyst expertise; time and resources available; the type of project; and the problem for which the method was being used. When a method is being used creatively then high reliability, either for an individual analyst or across different analysts, may be undesirable, as it could restrict the range of alternatives considered. By way of contrast, in large, safetycritical, projects with a number of analysts, a much higher degree of reliability is necessary, as the results achieved by the different analysts will no doubt need integrating at some stage during the project.

If reliability is not a simple concept, then validation is even more challenging. There are four types of validity for HFE methods: construct, content, concurrent, and predictive. Construct validity concerns the 
underlying theoretical basis of a method. Content validity is concerned with the credibility that a method is likely to gain among its users. They suggest that, ideally, a method should use appropriate terminology and language and seem up to the job of analysis if it is to be taken seriously. Obviously, such validity requires agreement among those using the methods. Finally, concurrent and predictive validity address the extent to which an analyzed performance is representative of the performance that might have been analysed. The difference between concurrent and predictive validity is a matter of time: concurrent validity describes current performance sampled whereas predictive validity concerns the performance of the future. What is important is that HFE methods possess a level of concurrent or predictive validity suitable for their application. There continues to be debate over the role of validation in HFE (Annett, 2002; Stanton \& Young, 1999b; Stanton, 2002, 2014), and the issues are by no means resolved. The goal of the discipline for methods should be to meet both reliability and validity criteria. Although laboratory and other research work may be a desirable minimum, it is the perceptions of ultimate users in the design and engineering industries that will be most important."

\subsection{Summary of perspectives on the reliability and validity of HFE methods}

A summary of each perspective on the reliability and validity of HFE methods is presented in Table 3.

\section{4 | PREDICTION}

Accurately forecasting the behavior of individuals, teams, organizations, and even entire systems has been labeled one of the greatest challenges facing HFE (Moray, 2008; Salmon, Walker, et al., 2017; Stanton \& Stammers, 2008). The majority of HFE methods cannot predict behavior beyond the relatively simple case of deterministic error-producing conditions (Kirwan, 1992). This is particularly problematic in the realm of systems HFE whereby the requirement to predict encapsulates both individual operator but also overall system behavior. Though methods such as Cognitive Work Analysis (CWA; Vicente, 1999), the Event Analysis of Systemic Teamwork (Stanton et al., 2018), and the Systems Theoretic Accident Model and Processes (Leveson, 2004) provide the capacity to comprehensively model complex systems, the outputs are static and cannot be used to simulate system behavior. Consequently, systems HFE methods cannot be used to make valid predictions about the behavior of a particular system following HFE intervention (Salmon et al., 2020). This is often required by end-users or project stakeholders who need to understand the likely impact of interventions to support decision making regarding implementation. While many HFE scholars have emphasized the need for predictive systems HFE methods, they have not been forthcoming. Here, each co-author was asked if prediction in systems HFE is possible, and if so, what is required to enable it.

TABLE 3 A summary of perspectives on the reliability and validity of HFE methods (authors are de-identified for blinded review process)

\begin{tabular}{|c|c|c|c|}
\hline & $\begin{array}{l}\text { Do HFE methods require } \\
\text { evidence of reliability and } \\
\text { validity? }\end{array}$ & $\begin{array}{l}\text { Why is the reliability and validity of HFE methods } \\
\text { not often tested? }\end{array}$ & How can this be resolved? \\
\hline Salmon & No (Reliability) & $\begin{array}{l}\text { 2. There is limited guidance available on how best to } \\
\text { design, conduct, and analyze reliability and } \\
\text { validity studies. }\end{array}$ & \\
\hline Read & $\begin{array}{l}\text { Not in all cases (e.g., design } \\
\text { methods) }\end{array}$ & $\begin{array}{l}\text { 1. Too much focus on the development of new HFE } \\
\text { methods }\end{array}$ & $\begin{array}{l}\text { 1. Identify a set of core HFE methods and conduct } \\
\text { formal reliability and validity studies }\end{array}$ \\
\hline Hulme & Yes & $\begin{array}{l}\text { 1. It is too challenging, combined with a lack of } \\
\text { knowledge and expertize }\end{array}$ & \\
\hline Walker & Yes & 1. It is too challenging & $\begin{array}{l}\text { 1. Develop a shared understanding of HFE's } \\
\text { underlying epistemology and ontology }\end{array}$ \\
\hline Stanton & Yes & $\begin{array}{l}\text { 1. Many reasons, including the lack of funding, time, } \\
\text { understanding, and experience among others }\end{array}$ & $\begin{array}{l}\text { 1. A stated goal of the HFE discipline should be } \\
\text { for its methods to meet set reliability and } \\
\text { validity criteria }\end{array}$ \\
\hline Stevens & Yes & $\begin{array}{l}\text { 1. It can be in the too hard basket, but it is not solely } \\
\text { a challenge for HFE. }\end{array}$ & $\begin{array}{l}\text { 1. Ensure the quality of both doctoral candidates } \\
\text { and their supervision. }\end{array}$ \\
\hline
\end{tabular}

Abbreviation: HFE, Human Factors and Ergonomics. 


\subsection{From a HFE perspective, is accurate prediction actually possible?}

Stanton: "As Niels Bohr (the Nobel prize willing theoretical physicist) once observed: "Prediction is very difficult, especially if it's about the future." That is especially true in HFE, with the complexities of the interactions in sociotechnical systems. It is probably fair to say, the simpler the system and the narrower the prediction, the easier it is to anticipate behaviour (Stanton, 2016). HFE methods have had some notable successes and failures in this regard (Stanton \& Young, 1999a). For example, studies using methods such as SHERPA, HET, and TAFEI have been able to predict some of the errors that are observed in system use (Stanton \& Stevenage, 1998; Stanton et al., 2009). Making predictions about the performance of broader aspects of more complex systems is another matter."

Walker: "If your HFE problem is well understood with relatively slow rates of change and few component parts, prediction is eminently possible. If your HFE problem is of strategic importance to the discipline (Dul et al., 2012), i.e. not fully understood, with high rates of change, and multiple components, then the range of existing HFE methods is limited, and the methods capable of meaningful prediction is virtually nil. Even those currently available to tackle these systems problems are largely restricted to pen and paper, or the most basic desktop software, so scale poorly. This is a distinct disadvantage when the future direction is 'massive sociotechnical systems' (Holman, Walker, Lansdown, \& Hulme, 2020; Holman, Walker, Lansdown, Salmon, et al., 2020). There is a subtlety of course. Insight derived from HFE methods can lead to a form of prediction which manifests itself as decision-support. Prediction in a very loose sense."

McLean: "From a team sports perspective, No. I think HFE methods have great potential in this area though. At present, HFE methods can help explain recurring patterns of behaviours at a team level that will occur during a match, which can assist the design of training practice. However, predicting what the opposition and individuals will do across an entire match is out of reach at this point. The match analysis technology we currently have combined with the expertise of coaches are equal or better than what any HFE methods can currently achieve. Coaches will design training to prepare for the behaviours and patterns of other teams at a macro level, but prediction at the micro and meso levels are not possible. Big data is currently being used in sport science to understand the variables that supposedly predict successful outcomes. However, the problem is that the innumerable interactions and influences on performance are being reduced down to one or two variables. It is impossible to understand sports performance by reducing the complexity of sport into a few variables (Salmon \& McLean, 2020). I think this is where systems HFE will have a big impact in the coming years, by moving the discipline away from reductionism."

Stevens: "Not in any work that I have been involved in first-hand. While the term 'accurately' is contestable; there does however exist the ability to identify a range of plausible futures for anticipated individuals, teams, organisations, and even systems. Does it only move toward prediction if those futures are played out as exactly anticipated? Is it perhaps enough to be able to identify aspects of anticipated or expected behaviour? Then via appropriately designed systems it is possible to influence humans in those systems so that they do not behave in any unanticipated ways-in essence a welldesigned space will afford predictable behaviour and that is sufficient. I can imagine that this is possibly a true scenario for some designs in my domain of urban development."

Hulme: "In other academic disciplines, be it the epidemiologic, public health, or business and economic fields, there has been such a thing as "behavioural prediction" for some time. For example, statistical techniques such as multiple regression analyses can help researchers to 'predict' the value of outcome $y$ given the value of exposure $x$ whilst accounting for the influence of several other explanatory variables. Indeed, regression modelling is frequently used in sports injury aetiology and prevention research to better understand which biologic and behavioural exposures best explain injury occurrence. If following the analysis, a linear pattern is observed, and the coefficient of determination is nearing 1.0, we can say that the model fits the data well and can be useful for making predictions about some unknown phenomenon or value (e.g., what is the risk of injury if an athlete is heavier, faster, or switches footwear?). More advanced forms of statistical analyses, probability modelling require the disclosure of any underlying model assumptions and error. In addition, whilst prediction is the estimation of an outcome based on observed association, causality is the identification of the mechanisms and processes by which the outcome is generated. Thus, 'accurate' prediction requires that we can also explain the aetiological basis of phenomena. Prediction may be possible depending on the context, research purpose, adopted analytical approach, and the extent to which study limitations have been accounted for and reported. What this all means is that HFE research may have to explore other methods and analytical approaches in which to attempt to predict the behaviour of individuals, teams and systems."

Read: "I think 'prediction' needs some definition. Are we talking about prediction of specific behaviours? Or broad predictions that certain behaviours or classes of behaviours could emerge over time or contexts? If the former, then my answer is no. If we accept that much of our work is investigating complex systems, where we know that performance is variable and adaptive, changing to cope with the changing constraints of our environments, the notion of being able to predict a specific behaviour occurring at a specific point in time seems incongruous with complex systems approaches.

If the latter, then we do have methods that can identify possibilities for behaviour-such as CWA.

If we take a complex systems perspective, any form of accurate, specific prediction is not possible, and indeed not useful. Systems theory tells us that systems are dynamic, we build models to describe them, but by the time the model is finalised, the system has likely changed already (Dekker, 2011). Even the process of building the model and having it say, validated by SMEs, while only a small intervention, can create non-linear effects that propagate throughout the system. For example, a senior management SME may gain some insight from reviewing the systems model, and begin to subtly 
change their decision-making that subsequently creates large changes in the organisation. Thus, any predictions made on the basis of that model in fact no longer apply and could in fact lead to a focus on dealing with the wrong issues.

I do agree that it is useful for organisations and governments to have a better understanding of risk and the ways in which risk may play out, but I would advocate less for specific predictions, and more for better understanding of risk from a systemic perspective and better strategies for managing risk. I wonder if accurate prediction could lead us to a false sense of security, and to have blind spots when the context changes. Instead, perhaps we should be building a mindset of uncertainty, and supporting adaptation and flexibility to deal with new risks and issues as they emerge."

Salmon: "Given the complexity of HFE problem spaces our methods are never going to be $100 \%$ accurate in predicting behaviour (no method can be if the system is truly complex); however, I feel strongly that HFE methods, can be used to provide useful predictions of behaviour or system dynamics. For example, methods such as CWA (Vicente, 1999), EAST (Stanton et al., 2018), FRAM (Hollnagel, 2012) and Net-HARMS (Dallat et al., 2018) can provide useful predictions about individual, team, organisational or system behaviour. We cannot predict when and where something will occur, but we can identify the kinds of behaviours or dynamics that a system might exhibit.

On top of this, I think methods from other areas can also be usefully applied in HFE-for example computational modelling approaches such as Agent-Based Modelling (ABM) and system dynamics (e.g. Read et al., 2020; Salmon et al., 2020; Thompson et al., 2020). These methods bring a useful quantitative aspect to system modelling, enabling us to assess the likely dynamics of a system's behaviour over time."

\subsection{What is required to enable accurate prediction in HFE?}

Walker: "A radical systems agenda. Without the rapid development of appropriate methodology, HFE is in serious danger of becoming an afterthought in global trends surrounding the current 4IR. The complexity created by $4 \mathrm{IR}$ technologies seems to be rapidly outpacing the realisation of Dul et. al's (2012) strategic direction for the discipline, a direction which seems increasingly timid and parochial. New types of HFE methods are needed now more than ever (Hollman et al., 2020; Salmon, Walker, et al., 2017). Specifically:

- Methods with capability to model the interaction between humans and autonomous agents for effective allocation of function in post-dualistic sociotechnical systems (i.e. where Al might mean the human is no longer the 'prime agent').

- The capability of modelling emergence in complex interconnected 4IR systems to understand and predict latent risks and opportunities.
- The capability to perform multilevel analysis of truly massive sociotechnical systems.

- Methods which can be implemented with more than a pen and some paper(!).

Good luck with all that."

Stanton: "If it isn't possible to validate HFE methods we should not be making predictions. The purpose of predictions is to anticipate future behaviour and make decisions to improve performance (such as safety, effectiveness, and work satisfaction). No prediction will be perfect, but is should be good enough for the job at hand. For example, when making predictions about driver performance with invehicle technology, we were able to demonstrate that the predictions were reasonable when compared with drivers performing the tasks in a driving simulator (Harvey \& Stanton, 2013). If the predictions of system performance are not proven to be valid, then the assumptions upon which decisions to improve performance will be false. This could, potentially at least, result in making the system worse rather than better. When dealing with engineering colleagues in a wide variety of industries (aviation, defence, energy distribution, ground transportation, and maritime) the gravitas with which HFE methods are treated very much depends upon proof that they actually work."

Salmon: "Further development of systems HFE methods as well as exploration of methods from other disciplines. For example, we have been exploring the integration of computational modelling methods such as $A B M$ and system dynamics with systems HFE methods (see Salmon \& Read, 2019; Salmon et al., 2020)."

Hulme: "HFE would benefit from applying or integrating traditional statistical approaches (e.g., General Linear Models, regression analyses) more frequently into its methodological toolkit. There are two required steps before the prediction of behaviour in complex systems is close to possible: (i) that a system is characterised by a set of tenets, principles or characteristics (e.g., Grant et al., 2018), and it is these tenets that are to be subject to modelling activities; and (ii) that the said modelling occurs in a dynamic, time continuous fashion which can be achieved with computational systems science modelling methods (i.e., simulation-based approaches). At present, a select group are the only HFE researchers to explicitly promote the use of ABM and System Dynamics (SD) modelling in the HFE space (e.g. Farid et al., 2019; Hettinger et al., 2015; Read et al., 2020; Salmon et al., 2020; Thompson et al., 2020), and more work is required to understand how dynamic computational modelling methods can be used to capture the 'emergent' nature of complex (sociotechnical) systems. In doing so, prediction-however accurate-might be within reach."

McLean: "I think the best chance is potentially with computational modelling methods such as systems dynamics and ABM integrated with HFE methods where thousands of simulations can be run. This area is where I think sport and HFE researchers and practitioners can learn from each other. Accurate prediction is paramount for safety critical domains, and the increasing availability 
TABLE 4 A summary of perspectives on HFE methods and the prediction of behavior (authors are de-identified for blinded review process)

\begin{tabular}{|c|c|c|}
\hline Author & From an HFE perspective, is accurate prediction actually possible? & What is required to enable accurate prediction in HFE? \\
\hline Salmon & $\begin{array}{l}\text { Yes, it is possible to develop useful predictions of a system's } \\
\text { behavior or dynamics. }\end{array}$ & $\begin{array}{l}\text { 1. Development and testing of new predictive HFE methods. } \\
\text { 2. Integration of computational modeling methods with systems } \\
\text { HFE methods. }\end{array}$ \\
\hline Read & Yes (broad predictions) & N/A (accurate prediction not possible) \\
\hline Hulme & Yes, depending on the context and aims of the study & $\begin{array}{l}\text { 1. Identification of the set of features which influence behavior. } \\
\text { 2. Use of computational modeling methods such as ABM and } \\
\text { System Dynamics. }\end{array}$ \\
\hline Walker & $\begin{array}{l}\text { Yes, for deterministic systems and in the provision of insight to } \\
\text { support decisions. }\end{array}$ & 1. Development and testing of new predictive HFE methods \\
\hline Stanton & Yes, but extremely difficult & $\begin{array}{l}\text { 1. Further reliability and validity testing of HFE methods in a } \\
\text { predictive context. }\end{array}$ \\
\hline Stevens & No & 1. Development and testing of new predictive HFE methods \\
\hline McLean & No & $\begin{array}{l}\text { 1. Integration of computational modeling methods with systems } \\
\text { HFE methods. }\end{array}$ \\
\hline
\end{tabular}

Abbreviation: HFE, Human Factors and Ergonomics.

of big data in sport could help HFE with its prediction efforts. However, transdisciplinary research is another issue altogether."

\subsection{Summary of perspectives on the reliability and validity of HFE methods}

A summary of each perspective on the issue of prediction is presented in Table 4.

\section{5 | CONCLUSION}

The aim of this article was to present a set of perspectives on three important issues surrounding the utility of systems HFE methods: the research-practice gap, reliability and validity, and the capacity to predict behavior. The perspectives presented demonstrate that each issue is nuanced in terms of causes; however, there is consensus on some strategies that could potentially form part of an agenda to resolve each issue. For the research-practice gap, the majority of contributors agreed that it exists and that both researchers and practitioners have a part to play in its resolution. Most of the strategies offered require the development of stronger partnerships between researchers and practitioners. This will provide the foundation to enable researchers to better understand practitioner needs and constraints as well as the involvement of end-users in research studies and method development. A final but pertinent strategy is enhanced organizational support for practitioners to engage with academia.

On the reliability and validity of HFE methods, again there was agreement that this is an issue and that evidence of reliability and validity is a critical requirement for systems HFE methods. The contributors largely agreed that the challenging nature of reliability and validity studies drives the issue, with the large amount of resources required and a lack of knowledge and guidance on how to conduct such studies acting as strong barriers. Moving forward, stricter requirements around the testing of systems HFE methods and improved guidance for the conduct of reliability and validity studies were offered as potential solutions. Clearly there is a need for further guidance and education around how reliability and validity can be tested.

The final issue discussed was the capacity of systems HFE methods to predict behavior. While most agreed that it is important, not all agreed that it is possible, and some suggested that it may be possible but is extremely difficult. There was agreement on the strategies required to enable prediction, however, with most suggesting the development and testing of new methods and in particular the integration of systems HFE methods with computational modeling methods such as ABM and SD. As argued by others, the training and use of computational modeling methods in HFE seems to offer a useful pathway toward a useful form of prediction (see Hettinger et al., 2015; Holman, Walker, Lansdown, Salmon, et al., 2020; Salmon \& Read, 2019; Salmon et al., 2020).

It is important to acknowledge two limitations. First, the perspectives of only seven researchers were included and thus the views presented cover only a small subset of systems HFE researchers. Further research should explore the use of a survey or Delphi study to explore the opinions of a larger sample. Second, the focus was specifically on systems HFE, with other areas of HFE such as physical and cognitive HFE deemed to be out of scope. It is therefore important to note that both the issues and potential solutions discussed may not apply in other areas of HFE. Further research should 
continue to explore issues impacting the quality of HFE in all of its core areas, including physical, cognitive, and systems HFE.

\section{ORCID}

Paul M. Salmon (D) http://orcid.org/0000-0001-7403-0286 Gemma J. M. Read (D) http://orcid.org/0000-0003-3360-812X Nicholas J. Stevens (D) http://orcid.org/0000-0003-0046-9362

\section{REFERENCES}

Annett, J. (2002). A note on the validity and reliability of ergonomics methods. Theoretical Issues in Ergonomics Science, 3(2), 228-232. https://doi.org/10.1080/14639220210124067

Cornelissen, M., Salmon, P. M., McClure, R., \& Stanton, N. A. (2014). Validating the strategies analysis diagram: Assessing the reliability and validity of a formative method. Applied Ergonomics, 45, 1484-1494.

Dallat, C., Salmon, P. M., \& Goode, N. (2018). Identifying risks and emergent risks across sociotechnical systems: The NETworked Hazard Analysis and Risk Management System (NET-HARMS). Theoretical Issues in Ergonomics Science, 19(4), 456-482.

Dekker, S. W. A. (2011). Drift into failure: From hunting broken components to understanding complex systems. Ashgate.

Dekker, S. W. A. (2015). The danger of losing situation awareness. Cognition, Technology \& Work, 17, 159-161.

de Ruijter, A., \& Guldenmund, F. (2016). The bowtie method: A review. Safety Science, 88, 211-218.

Dul, J., Bruder, R., Buckle, P., Carayon, P., Falzon, P., Marras, W. S., Wilson, J. R., \& van der Doelen, B. (2012). A strategy for Human Factors/Ergonomics: Developing the discipline and profession. Ergonomics, 55(4), 377-395. https://doi.org/10.1080/00140139. 2012.661087

Farid, M., Purdy, N., \& Neumann, P. (2019). Using system dynamics modelling to show the effect of nurse workload on nurses' health and quality of care. Ergonomics, 63(6), 1-37. https://doi.org/10. 1080/00140139.2019.1690674

Goncalves Filho, A. P., Jun, G. T., \& Waterson, P. (2019). Four studies, two methods, one accident-An examination of the reliability and validity of Accimap and STAMP for accident analysis. Safety Science, 113, 310-317.

Goode, N., Salmon, P. M., Lenne, M. G., \& Finch, C. (2018). Bridging the gap between accident prevention theory and practice. CRC Press.

Goode, N., Salmon, P. M., Taylor, N. Z., Lenné, M. G., \& Finch, C. F. (2017). Developing a contributing factor classification scheme for Rasmussen's AcciMap: Reliability and validity evaluation. Applied Ergonomics, 64, 14-26.

Grant, E., Salmon, P. M., Stevens, N. J., Goode, N., \& Read, G. J. M. (2018). Back to the future: What do accident causation models tell us about accident prediction? Safety Science, 104, 99-109.

Hancock, P. A. (2019). Some pitfalls in the promises of automated and autonomous vehicles. Ergonomics, 62(4), 479-495.

Harvey, C., \& Stanton, N. A. (2013). Modelling the hare and the tortoise: Predicting the range of in-vehicle task times using critical path analysis. Ergonomics, 56(1), 16-33.

Hettinger, L. J., Kirlik, A., Goh, Y. M., \& Buckle, P. (2015). Modeling and simulation of complex sociotechnical systems: Envisioning and analysing work environments. Ergonomics, 58(4), 600-614. https:// doi.org/10.1080/00140139.2015.1008586

Hollnagel, E. (2012). FRAM, the functional resonance analysis method: Modelling complex socio-technical systems. Ashgate.

Holman, M., Walker, G. H., Lansdown, T., \& Hulme, A. (2020). Radical systems thinking and the future role of computational modelling in ergonomics: An exploration of agent-based modelling. Human Factors, 63, 1057-1074. https://doi.org/10.1080/00140139.2019. 1694173
Holman, M., Walker, G., Lansdown, T., Salmon, P., Read, G., \& Stanton, N. (2020). The Binary-Based Model (BBM) for improved human factors method selection. Human Factors. https://doi.org/10.1177/ 0018720820926875

Hulme, A., Stanton, N. A., Waterson, P., Walker, G. H., \& Salmon, P. M. (2019). What do applications of systems thinking accident analysis methods tell us about accident causation? A systematic review of applications between 1990 and 2018. Safety Science, 117, 164-183.

International Ergonomics Association. (2019). What is ergonomics? https://iea.cc/what-is-ergonomics/. Accessed June 5, 2020.

Karsh, B. T., Waterson, P., \& Holden, R. J. (2014). Crossing levels in systems ergonomics: A framework to support 'mesoergonomic' inquiry. Applied Ergonomics, 45(1), 45-54.

Karwowski, W. (2005). Ergonomics and human factors: The paradigms for science, engineering, design, technology and management of humancompatible systems. Ergonomics, 48(5), 436-463.

Kirwan, B. (1992). Human error identification in human reliability assessment: II. Detailed comparison of techniques. Applied Ergonomics, 23(6), 371-381. https://doi.org/10.1016/0003-6870(92)90368-6

Leveson, N. G. (2004). A new accident model for engineering safer systems. Safety Science, 42(4), 237-270.

Leveson, N. G. (2011). Applying systems thinking to analyze and learn from events. Safety Science, 49, 55-64.

Moray, N. (2008). The good, the bad, and the future: On the archaeology of ergonomics. Human Factors, 50(3), 411-417.

Rifkin, J. (2014). The zero marginal cost society. Palgrave, McMillan.

Salmon, P. M. (2016). Bridging the gap between research and practice in ergonomics methods: Methodological Issues in Ergonomics Science Part II. Theoretical Issues in Ergonomics Science, 17(5-6), 459-467.

Salmon, P. M., Goode, N., Taylor, N., Dallat, C., Finch, C., \& Lenne, M. G. (2017). Rasmussen's legacy in the great outdoors: A new incident reporting and learning system for led outdoor activities. Applied Ergonomics, 59, 637-648.

Salmon, P. M., \& McLean, S. (2020). Complexity in the beautiful game: Implications for football research and practice. Science and Medicine in Football, 4(2), 162-167. https://doi.org/10.1080/24733938.2019. 1699247

Salmon, P. M., \& Read, G. J. M. (2019). Many-model thinking in systems ergonomics: A case study in road safety. Ergonomics, 62(5), 612-628.

Salmon, P. M., Read, G. J. M., Thompson, J., McLean, S., \& McClure, R. (2020). Computational modelling and systems ergonomics: A system dynamics model of drink driving-related trauma prevention. Ergonomics, 63(8), 965-980.

Salmon, P. M., Stanton, N. A., Read, G. J. M., Walker, G. H., Stevens, N. J, \& Hancock, P. A. (2019). From systems ergonomics to global ergonomics: The world as a socio-ecological-technical system. Ergonomics and Human Factors 2019, Global challenges, Global ergonomics, Stratford-Upon-Avon, April 2019.

Salmon, P. M., Walker, G. H., Read, G. J. M., Goode, N., \& Stanton, N. A. (2017). Fitting methods to paradigms: Are ergonomics methods fit for systems thinking? Ergonomics, 60(2), 194-205.

Shorrock, S. T., \& Williams, C. A. (2016). Human factors and ergonomics methods in practice: Three fundamental constraints. Theoretical Issues in Ergonomics Science, 17(5-6), 468-482.

Stanton, N. A. (2002). Developing and validating theory in ergonomics science. Theoretical Issues in Ergonomics Science, 3(2), 111-114.

Stanton, N. A. (2014). Commentary on the paper by Heimrich Kanis entitled 'Reliability and validity of findings in ergonomics research': Where is the methodology in ergonomics methods? Theoretical Issues in Ergonomics Science, 15(1), 55-61.

Stanton, N. A. (2016). On the reliability and validity of, and training in, ergonomics methods: A challenge revisited. Theoretical Issues in Ergonomics Science, 17(4), 345-353.

Stanton, N. A., Salmon, P., Harris, D., Marshall, A., Demagalski, J., Young, M. S., Waldmann, T., \& Dekker, S. W. A. (2009). Predicting 
pilot error: Testing a new methodology and a multi-methods and analysts approach. Applied Ergonomics, 40(3), 464-471.

Stanton, N. A., Salmon, P. M., Rafferty, L. A., Walker, G. H., Baber, C., \& Jenkins, D. (2013). Human factors methods: A practical guide for engineering and design (2nd ed). Ashgate.

Stanton, N. A., Salmon, P. M., \& Walker, G. H. (2018). Systems thinking in practice: Applications of the event analysis of systemic teamwork method. CRC Press.

Stanton, N. A., \& Stammers, R. B. (2008). Bartlett and the future of ergonomics. Ergonomics, 51(1), 1-13.

Stanton, N. A., \& Stevenage, S. (1998). Learning to predict human error: Issues of reliability, validity and acceptability. Ergonomics, 41(11), 1737-1756.

Stanton, N. A., \& Young, M. (1999a). What price ergonomics? Nature, 399, 197-198.

Stanton, N. A., \& Young, M. S. (1999b). A guide to methodology in ergonomics: Designing for human use (1st ed). Taylor \& Francis.

Svedung, I., \& Rasmussen, J. (2002). Graphic representation of accident scenarios: Mapping system structure and the causation of accidents. Safety Science, 40, 397-417.

Thatcher, T., Waterson, P., Todd, A., \& Moray, N. (2018). State of Science: Ergonomics and global issues. Ergonomics, 61(2), 197-213.

Thompson, J., Read, G. J. M., Wijnands, J., \& Salmon, P. M. (2020). The perils of perfect performance: Potential effects of introducing autonomous vehicles on crash rates for vulnerable road users. Ergonomics, 63(8), 981-996.

Thoroman, B., Salmon, P. M., \& Goode, N. (2020). Evaluation of construct and criterion-referenced validity of a systems-thinking based near miss reporting form. Ergonomics, 63(2), 210-224.

Vicente, K. J. (1999). Cognitive work analysis: Toward safe, productive, and healthy computer-based work. Lawrence Erlbaum Associates.

Walker, G. H. (2016). Fortune favours the bold. Theoretical Issues in Ergonomics Science, 17(4), 452-458.
Walker, G. H., Salmon, P. M., Bedinger, M., \& Stanton, N. A., (2017). Quantum ergonomics: shifting the paradigm of the systems agenda. Ergonomics, 60(2), 157-166.

Walker, G. H., Stanton, N. A., Salmon, P. M., Jenkins, D. P., \& Rafferty, L. (2010). Translating concepts of complexity to the field of ergonomics. Ergonomics, 53(10), 1175-1186.

Waterson, P., \& Sell, R. (2006). Recurrent themes and developments in the history of the Ergonomics Society. Ergonomics, 49(8), 743-799.

Wiegmann, D. A., \& Shappell, S. A. (2003). A human error approach to aviation accident analysis: The human factors analysis and classification system. Ashgate Publishing Ltd.

Williams, C., \& Salmon, P. M. (2016). The challenges of practice-oriented research. In S. Shorrock, \& C. Williams (Eds.), Human factors and ergonomics in practice: Improving system performance and human wellbeing in the real world. Ashgate.

Wilson, J. (2006). Fundamentals of systems ergonomics/human factors. Applied Ergonomics, 45(1), 5-13.

Wilson, P. F., Dell, L. D., \& Anderson, G. F. (1993). Root cause analysis: A tool for total quality management. ASQC Quality Press.

How to cite this article: Salmon PM, Read GJM, Walker GH, et al. Methodological issues in systems Human Factors and Ergonomics: Perspectives on the research-practice gap, reliability and validity, and prediction. Hum Factors Man. 2020;1-14. https://doi.org/10.1002/hfm.20873 